\title{
Comments: "Influence of physical training on bone mineral density in healthy young adults: a systematic review"
}

Sami A. Gabr 1,2

1. Professor of biochemistry and molecular biology, Rehabilitation research chair, College of Applied Medical Sciences, King Saud University, Riyadh, KSA. 2. Department of Anatomy, Faculty of Medicine, Mansoura University, Egypt. Correspondence: P.O. Box 10219 Riyadh 11433, KSA, email: nadalab2009@hotmail.com, dr.samigabr@gmail.com, sgabr@ksu.edu.sa

Aspects of human lifestyle such as diet, physical activity, and daytime life have positive effects on bone health, especially on bone loss or osteoporosis among older people. ${ }^{1-4}$

Many parameters such as genetic factors, peak bone mass (PBM), balanced nutrition, physical activity, and lifestyle risk factors, including the intake of caffeine, tea, and carbonated beverage, smoking, and alcohol consumption were collectively influencing changes in bone contents and mass among younger and older individuals. ${ }^{1-6}$ These parameters represent the main factors that affect the accumulation and maintenance of bone mass.,6 Moreover, anthropometric data (body weight and body mass index [BMI]) are also considered as related factors that contribute to changes in total bone mass..$^{5-7}$ Two studies have reported that high BMD is closely associated with elevated $\mathrm{BMI}$ in women, ${ }^{7}$ and that obesity significantly decreases the risk for osteoporosis, but does not decrease the risk for osteopenia. ${ }^{5,6}$

The strength of healthy bones can be assessed by continuous measurements of bone quality, bone mineral density (BMD), and bone structure. ${ }^{8,9}$ Currently, these parameters are considered the ideal controlled measures for bone strength in cases of healthy and diseased bones and are particularly affected by the scores of physical activity. ${ }^{10-12}$

As explained from the physiology of bone, its formation is predominant during the first ten years of human growth. A homeostatic balance between the naturally occurring processes of bone formation and resorption among was observed among healthy humans aged 20-45 yrs. In older ages, a disorder in the balance state occurs via a slight increase in the resorption process, which in turn results in bone loss and a lower bone density. ${ }^{13}$ It has been reported that individuals with low physical activity were susceptible to bone disorders, including bone loss or osteoporotic fracture. ${ }^{14}$ Conversely, physically active people, even those who are older, resist the decrease in BMD, which reduces their risk of fracture. Furthermore, increased physical activity results in an increase in BMD and a concomitant decrease in BMI. ${ }^{15,16}$

Finally, supporting comments on the influence of physical training on bone mineral density among young adults, many research works have reported that physical activity provides positive effects on BMD via mechanical loading mechanisms. ${ }^{17-19}$ Also, in previous studies, body mass index, physical activity, low calcium consumption, and abnormal lifestyle have a role in bone mineral density and prognosis of osteoporosis in young adults. ${ }^{20}$ In addition, in younger ages (children and adolescents), low back pain (LBP) was shown to be linked with limited sun exposure, inadequate vitamin D diets, adiposity, lower PA, sedentary lifestyles, vitamin $25(\mathrm{OH})$ D deficiency, and lower levels of Ca, CK, and LDH. ${ }^{21}$ In the same way, training programs of different intensities, 
particularly aerobic exercises of moderate intensity, were found to protect bone and cartilage by regulating body trace elements that are involved in the bio- synthesis of bone matrix structures and inhibition of bone resorption process via a proposed anti-free radical mechanism. ${ }^{22,23}$

\section{REFERENCES}

1. Lee I-M. Physical activity, fitness, and cancer. In: Bouchard C, Shephard RJ Stephens T, eds. Physical activity, fitness, and health. Champaign: Human Kinetics; 1994. p.814-31.

2. Buchner DM, Beresford SAA, Larson EB, LaCroix AZ, Wagner EH. Effects of physical activity on health status in older adults. II. Intervention studies. Annu Rev Public Health. 1992;13:469-88.

3. Lin YC, Huang LH, Yeh MC, Tai J). Leisure-time physical activities for community older people with chronic diseases. J Clin Nurs. 2011;20(7-8):940-9.

4. WHO: Scientific Group on the Prevention and Management of Osteoporosis. Prevention and management of osteoporosis: report of a WHO Scientific Group, Geneva, PA. Geneva: World Health Organization; 2000. p.1-3.

5. Ralston $\mathrm{SH}$. Bone mass through the lifespan. Women's Health Med 2006;3(4):145-8.

6. Korkmaz N, Tutoğlu A, Korkmaz I, Boyacı A. The relationships among vitamin D level, balance, muscle strength, and quality of life in postmenopausal patients with osteoporosis. J Phys Ther Sci. 2014;26(10):1521-6.

7. Handa R, Ali Kalla A, Maalouf G. Osteoporosis in developing countries. Best Pract Res Clin Rheumatol. 2008;22(4):693-708.

8. NIH Consensus Development Panel on Osteoporosis Prevention, Diagnosis, and Therapy. Osteoporosis prevention, diagnosis, and therapy. JAMA. 2001;285(6):785-95.

9. Cho JH, Kim MT, Lee HK, Hong IS, Jang HC. Factor analysis of biochemical markers associated with bone mineral density in adults. I Phys Ther Sci. 2014;26(8):1225-9.

10. Tanaka R, Ozawa J, Umehara T, Kito N, Yamasaki T, Enami A. Does exercise intervention improve muscle strength and balance of Japanese subjects with osteoporosis? A systematic review and meta-analysis of randomized controlled trials. J Phys Ther Sci. 2013;25(4):397-401.

11. Ammann P, Rizzoli R. Bone strength and its determinants. Osteoporos Int. 2003; 14(suppl. 3):S13-8.

12. Kanis $\mid A$, Borgstrom $F$, De Laet $C$, Johansson $H$, Johnell $O$, Jonsson $B$, et al. Assessment of fracture risk. Osteoporos Int. 2005;16(6):581-9.

13. Johnell $O$, Kanis JA, Oden A, Johansson H, De Laet C, Delmas P, et al.
Predictive value of BMD for hip and other fractures. | Bone Miner Res. 2005;20(7):1185-94

14. Morin S, Leslie WD, Manitoba Bone Density Program: high bone mineral density is associated with high body mass index. Osteoporos Int. 2009;20(7):1267-71.

15. Han J-T, Lee S-Y. A comparison of vital capacity between normal weight and underweight women in their 20s in South Korea. J Phys Ther Sci. 2012;24(5):379-81.

16. Andreoli A, Bazzocchi A, Celi M, Lauro D, Sorge R, Tarantino U, et al. Relationship between body composition, body mass index and bone mineral density in a large population of normal, osteopenic and osteoporotic women. Radiol Med (Torino). 2011;116(7):1115-23.

17. Fu X, Ma X, Lu H, He W, Wang Z, Zhu S. Associations of fat mass and fat distribution with bone mineral density in pre- and postmenopausal Chinese women. Osteoporos Int. 2011;22(1):113-9.

18. Moayyeri $A$. The association between physical activity and osteoporotic fractures: a review of the evidence and implications for future research. Ann Epidemiol. 2008;18(11):827-35.

19. Langsetmo L, Hitchcock CL, Kingwell EJ, Davison KS, Berger C, Forsmo $\mathrm{S}$, et al. Canadian Multicentre Osteoporosis Study Research Group: Physical activity, body mass index and bone mineral density-associations in a prospective population-based cohort of women and men: the Canadian Multicentre Osteoporosis Study (CaMos). Bone. 2012;50(1):401-8.

20. Alghadir AH, Gabr SA, Al-Eisa E. Physical activity and lifestyle effects on bone mineral density among young adults: sociodemographic and biochemical analysis. J Phys Ther Sci. 2015;27(7):2261-70.

21. Alghadir AH, Gabr SA, Al-Eisa ES. Mechanical factors and vitamin D deficiency in schoolchildren with low back pain: biochemical and cross-sectional survey analysis. J Pain Res. 2017;10:855-65.

22. Alghadir AH, Gabr SA, Al-Eisa ES, Alghadir MH. Correlation between bone mineral density and serum trace elements in response to supervised aerobic training in older adults. Clin Interv Aging. 2016;11:265-73.

23. Avilla JA, Avila RA, Gonçalves EM, Guerra-Junior G. Influence of physical training on bone mineral density in healthy young adults: a systematic review. Rev Assoc Med Bras, 2019, 65 (8) 1102-1106 